Rakenteiden Mekaniikka (Journal of Structural Mechanics)

Vol. 50, No 3, 2017, pp. 271-274

https://rakenteidenmekaniikka.journal.fi/index

https://doi.org/10.23998/rm.65161

(c)Authors(s) 2017.

Open access under CC BY-SA 4.0 license.

\title{
Micromechanical modeling of failure behavior of metallic materials
}

\author{
Anssi Laukkanen ${ }^{1}$, Matti Lindroos, Tom Andersson, Tuukka Verho, Tatu Pinomaa
}

Summary. This extended abstract summaries results on exploitation of micromechanical modeling for failure mechanisms of metallic materials and microstructures.

Key words: crystal plasticity, microstructure, micromechanics, finite element method

Received 1 July 2017. Accepted 12 August 2017. Published online 21 August 2017.

\begin{abstract}
Microstructural and micromechanical modeling is arising as a key material modeling technique providing numerical modeling capabilities with an improved description of critical material features and mechanisms. Material characteristics such as microstructural morphologies, individual phases and defects can be included explicitly in numerical models and their significance to the material properties and performance measures of interest quantified. Similarly, mechanisms dependent on microstructural scale mechanisms such as polycrystalline plasticity can be modeled accounting for such anisotropic phenomena, and as such, improved accuracy can be reached with respect to design critical mechanisms such as cleavage fracture and initiation of short fatigue cracks.

Micromechanical modeling deals with evaluating and modeling material failure relevant mechanisms at the scale of the material microstructure. Typical example is material damage with respect to ductile or brittle fracture, fatigue damage and crack initiation, or for example analysis of material wear which can be seen as a more intricate failure process where several mechanisms interact across multiple spatial scales. Current work addresses some typical failure mechanisms of metallic materials at the scale of the material microstructure. Case studies are discussed where micromechanical modeling is employed to assess material failure with different damage mechanical
\end{abstract}

${ }^{1}$ Corresponding author. Anssi.Laukkanen@vtt.fi 
models and concepts. The basis in all is the description of material deformation by crystal plasticity constitutive models. Two treatments of damage are considered: direct coupling of the crystal plasticity model to a damage mechanical approach and a simpler methodology where a non-coupled evaluation of damage parameters is considered. The use cases consist of fracture, fatigue and wear problems from problems targeting both design of new materials, optimization of material solutions and improved design of products and components.

Key capability for explicit micromechanical modeling is the ability to model material microstructures. Various approaches have been proposed and developed (see $[1,2]$ for further details of the utilized methods), and an example of a method which uses electron backscatter diffraction (EBSD) data to describe the distribution of orientation in a metallic microstructure is presented in Figure 1. The approach is based on reconstruction and further segmentation of the microstructure, the reconstructured prior austenite microstructure presented in Figure 1a and the description containing all the sub-hierarchies of a martensite morphology in Figure 1b. Followingly, the crystal plasticity model can be employed e.g. to model tensile response, as has been done in Figure 1c-d. In assessing material damage researchers utilize two principal means. One based on performance indicators, another directly incorporating damage as a part of the crystal plasticity evaluation. The former can be argued to be simplistic and lose much of the information and finesse of the crystal plasticity results, but several researchers [3] have still found it produces sensible results and appears able to incorporate microstructural details to a degree. Example of such for evaluation of fatigue damage and strain life of an additively manufactured Ti-6-4 alloy is presented in Figure 2, where different microstructures are subjected to identical cyclic loads and the results inferred utilizing approaches presented in [3]. The microstructures contain both lamellar like features in addition to initial defects, particularly pore and crack like defects. In relation to work carried out [4] a far more extensive analysis is presented in Figure 3 with respect to wear of materials. Crystal plasticity model is utilized to identify the influence of surface loading conditions to surface damage (Figure 1a, followed by localization step) and process a material wear rate (Figure 1b, results of homogenization step), enabling the micromechanical assessment of cumulative wear.

Micromechanical modeling is crucial with respect to the ability to link microstructural scale material features to the actual operating conditions of the material critical to component and product performance. It is also expected to yield improved abilities for design by circumventing the need to introduce as many phenomenologies or empirical elements to design procedures and engineering methods. Current work presented cases where work is being pursued to this effect. 
a)

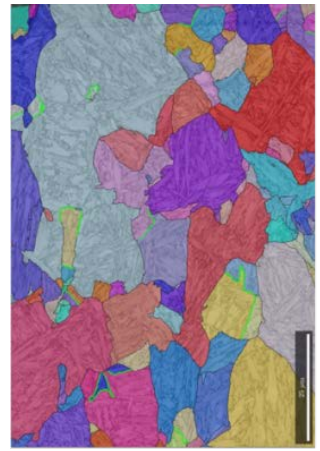

c)

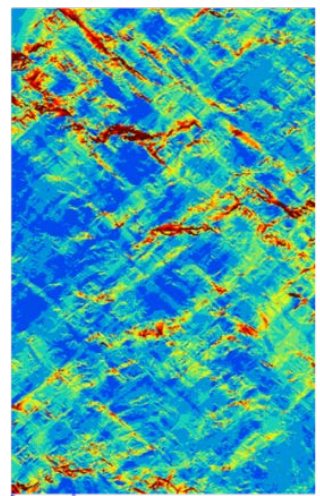

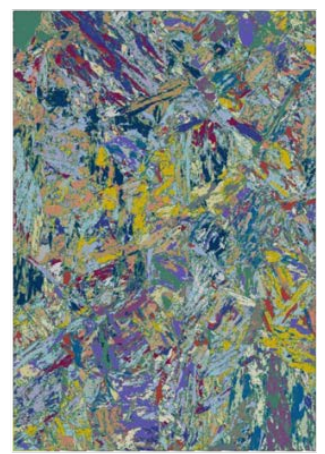

b)

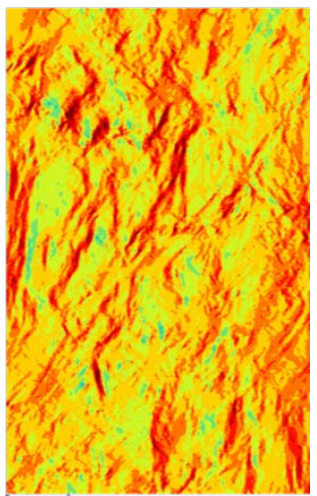

d)

Figure 1. Crystal plasticity modeling of a martensite Raex 500 microstructure during a tensile test: a) reconstructed prior austenite grains, b) finite element model materials, c) cumulative plastic slip and d) $1^{\text {st }}$ principal stress contours.

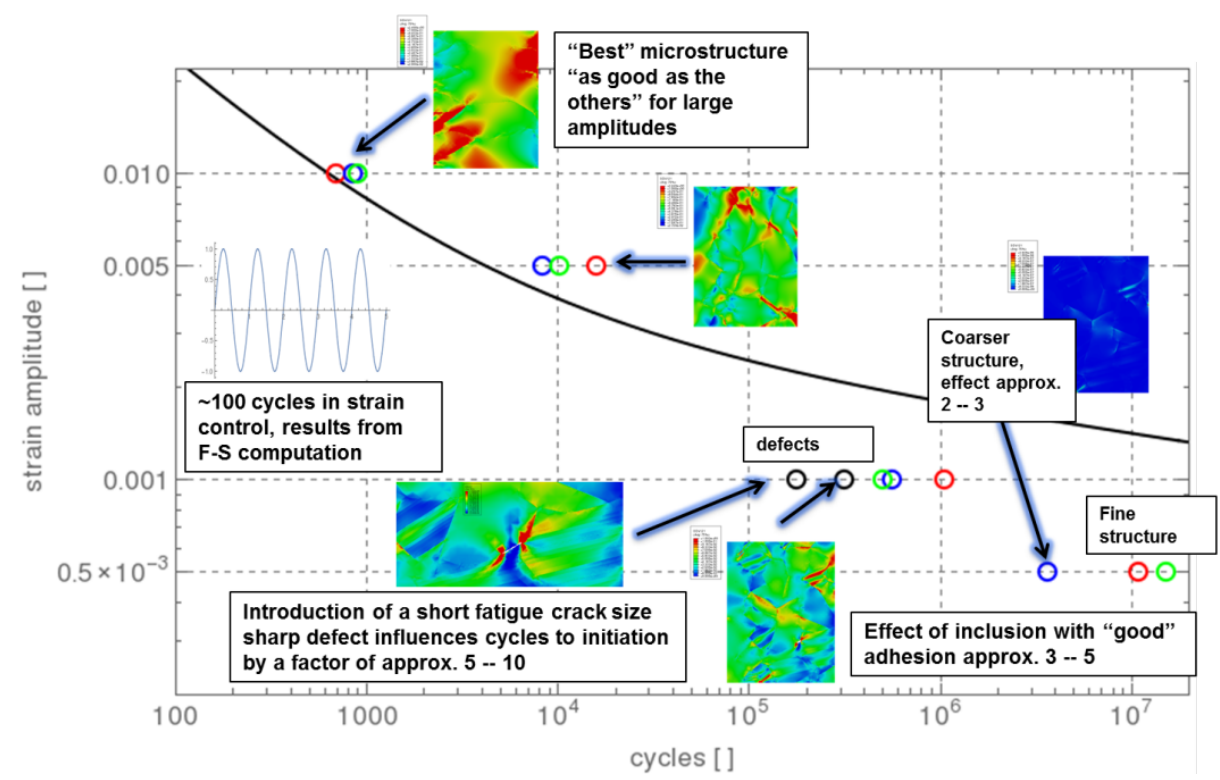

Figure 2. Micromechanical crystal plasticity based evaluation of Ti-6-4 alloy strain life. 
a)
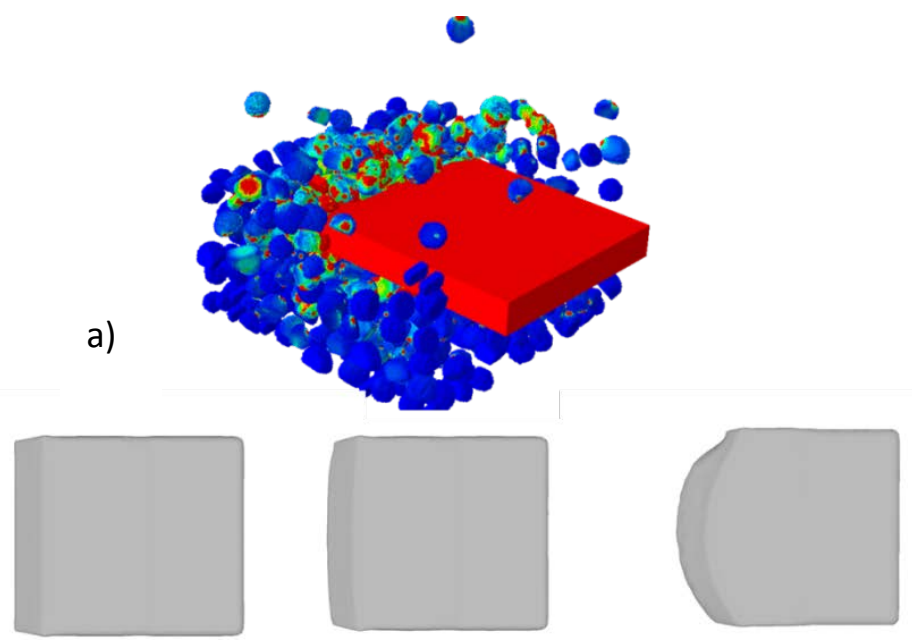

b)
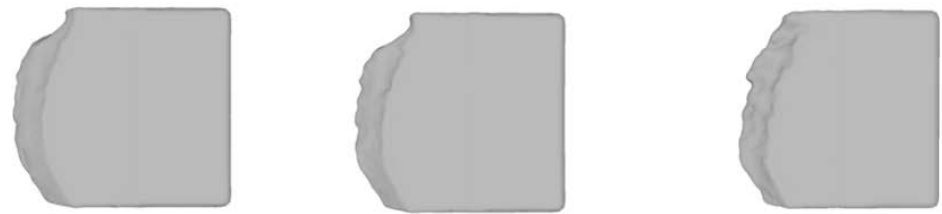

Figure 3. "FE2" wear analysis of a RAEX500 steel, a) macroscale evaluation of loading conditions and followed by localization b) results of wear rate homogenization and evolution of cumulative wear of a cutting edge.

\section{References}

[1] Holmberg, K., Laukkanen, A., Ghabchi, A., Rombouts, M., Turunen, E., Waudby, R., Suhonen, T., Valtonen, K., Sarlin, E. (2014). Computational modeling based wear resistance analysis of thick composite coatings. Tribology International, 72, pp. 13-30. https://doi.org/10.1016/j.triboint.2013.12.001

[2] Laukkanen, A., Pinomaa, T., Andersson, T., Holmberg, K. (2016). Effective interface model for design and tailoring of WC-Co microstructures. Journal of Powder Metallurgy, 59 (1), pp. 20-30.

https://doi.org/10.1080/00325899.2015.1130960

[3] Dabiri, M., Laukkanen, A., Bjork, T. (2015). Fatigue microcrack nucleation modeling: a survey of state of the art. International Review of Mechanical Engineering, 9 (4), pp. 368-376. https://doi.org/10.15866/ireme.v9i4.6231

[4] Lindroos, M., Valtonen, K., Kemppainen, A., Laukkanen, A., Holmberg, K., Holmberg, K. Kuokkala, V-T. (2015). Wear behavior and work hardening of high strength steels in high stress abrasion. Wear, 322-323, pp. 32-40. https://doi.org/10.1016/j.wear.2014.10.018

Anssi Laukkanen, Matti Lindroos, Tom Andersson, Tuukka Verho, Tatu Pinomaa VTT Technical Research Centre of Finland

P.O Box 02044, VTT Finland

Anssi.Laukkanen@vtt.fi 